\section{Telejornalismo: onde está o lead?}

\section{RESUMO}

O noticiário televisivo é a principal informação que a maioria dos brasileiros têm do mundo que os cerca. Nesse sentido, 0 telejornal ocupa uma dimensão significativa na construção da realidade. Este trabalho tem como objetivo discutir como o lead se apresenta na notícia de televisão e toma por base a perspectiva do newsmaking que estuda a produção da notícia a partir da cultura profissional dos jornalistas, da organização do trabalho e dos processos produtivos.

\section{ABSTRACT}

From the point of view of the newsmaking perspective, this article discusses the lead within the construction of television news.

\section{Alfredo Vizeu ${ }^{1}$}

Professor UFES e Professor licenciado Unisinos Jô Mazzarolo ${ }^{2}$

Mestranda em Comunicação/UFRJ

\section{Introdução}

EM ABRIL DESTE ano, mais precisamente no dia 23, o Jornal Nacional, da Rede Globo, principal noticiário televisivo do País, levava ao ar as primeiras imagens da seca no nordeste do Brasil. Uma semana depois, uma nova reportagem, mostrava a distribuição de donativos aos flagelados. Três dias após as câmeras da Globo registravam o saque de alimentos por parte dos atingidos pela seca.

A seca, até então um problema esquecido pelas autoridades, ao ganhar visibilidade na mídia, entra na pauta das preocupações do Governo motivando até uma visita do presidente da República, Fernando Henrique Cardoso, à região para ver de perto seus efeitos.

Sem entrar no mérito da questão da seca, um fenômeno que faz parte da vida deste País e parece longe de uma solução, interessa-nos no fato chamar a atenção para a força que a mídia, em particular a televisão, ocupa na sociedade. É partir do noticiário televisivo que o Governo é acionado e não o contrário, como seria de se esperar. A televisão é hoje, através do telejornal, a grande "Praça Pública" onde os temas nacionais são mostrados e debatidos dentro das regras próprias do veículo(Fausto Neto, 1995).

Num País como o nosso onde, na maioria das vezes, a única informação que as pessoas têm do mundo que as cerca é a transmitida pelo telejornal, esse quadro ganha uma dimensão maior. No entanto, apesar da importância que o telejornalismo tem para sociedade brasileira, a bibliografia e os estudos sobre o assunto ainda não são muitos diante da relevância do tema (Marques de Melo,1995; Caparelli \& Stumpf, 1998).

Este trabalho tem por objetivo discutir um dos aspectos do complexo campo do telejornalismo: a notícia, mais especifica- 
mente o lead, definido tradicionalmente, pela maioria dos autores, como a abertura, a parte mais importante da matéria jornalística, o parágrafo sintético que deve procurar responder às tradicionais perguntas: o quê?, quem?, quando?, onde?, como? e por quê? (Amaral, 1978, p.66-68).

A definição que toma por base a notícia de jornal também vale para a televisão? Esse é o ponto principal que pretendemos discutir. Longe de procurarmos dar uma resposta definitiva à questão, interessa-nos levantar alguns aspectos para novas pesquisas e debates sobre o tema. Como lembra Leon Sigal (1986) saber como as notícias são produzidas é a chave para compreender o que significam.

A informação é a principal matériaprima das instituições jornalísticas que ocupam um lugar central no desenvolvimento do capitalismo brasileiro e devem estar em constante vigilância pela sociedade, uma vez que cumprem uma função relevante na construção social da realidade (Berger; Luckmann, 1995).

Nesse sentido, entendemos que buscar revelar os modos de elaboração da notícia contribui não só para a reflexão sobre a atividade jornalística, mas para o próprio aperfeiçoamento democrático da sociedade.

Com a finalidade de contextualizar o debate, este estudo está divido em três momentos. Num primeiro, mesmo que de uma forma superficial e sucinta, faremos um breve histórico sobre o surgimento do lead no jornalismo e sua introdução no Brasil. Depois, mais em nível exemplificativo, apontaremos algumas diferenças que acreditamos existir entre as notícias de jornal e as de televisão. Finalmente, o tema central desta pesquisa: o lead na notícia televisiva.

\section{Os caminhos do lead}

São várias as explicações para o surgimento do lead no jornalismo. A mais correspondentes nos campos de batalha deram início a uma nova forma de escrever e publicar notícias. O autor explica que depois das lutas, os jornalistas dirigiam-se ao telégrafo para passar suas matérias. Por uma questão de tempo, eles pediam preferência para transmitir suas mensagens.

Fontcuberta (1993) diz que por causa da pressão do "relógio", os correspondentes evitavam emitir opiniões em suas reportagens. Além disso, eles deixavam de lado os detalhes, preocupando-se com o "essencial", os acontecimentos mais importantes. É que cada um queria enviar o mais rápido possível às redações as informações sobre o conflito. Além disso, o correio não podia parar só para atender os repórteres.

Diante deste quadro, os operadores do telégrafo criaram um método para dar preferência aos correspondentes. Cada jornalista podia ditar um parágrafo, o mais importante da sua informação. Ao terminar a primeira rodada, iniciava-se uma nova e assim sucessivamente até que todos conseguissem passar suas reportagens.

Segundo Fontcuberta, essa é a origem da pirâmide invertida da notícia, método que segue vigente ainda hoje. O núcleo da informação, o mais importante, se põe no princípio, denominado de lead. Os detalhes que complementam a notícia seguem em ordem de maior a menor importância até o final.

No estudo sobre a evolução histórica da imprensa nos Estados Unidos, Alejandro Pizarroso Quintero revela que a Guerra da Secessão determinou importantes modificações na imprensa. As tiragens dos jornais aumentaram muito e as técnicas de impressão tiveram de melhorar para atender a este novo quadro.

No entender de Quintero(1996), a generalização do telégrafo modificou a redação das notícias: desenvolveu assim o que conhecemos como lead ou entrada, onde a informação era resumida com a máxima economia de palavras.

No Brasil, o lead foi introduzido por Pompeu de Souza, em 1950, no Diário Carioca. De acordo com ele, citado por Genro 
(1987, p. 189), até então, a abertura da matéria era um comentário, uma opinião, uma mistura de informação, interpretação e tudo mais; a notícia ficava no final.

Sem dúvida, seria um reducionismo imputar a esses fatos históricos a explicação da consolidação da pirâmide no texto jornalístico. Não é este o nosso entendimento. A discussão sobre o a "pirâmide invertida" e o lead está ainda por se construir dentro de um contexto mais amplo de uma "teoria do jornalismo" (Traquina, 1993).

Para a maioria dos autores, o lead deve ser um resumo conciso das principais e mais recentes informações. Ele deve responder "às famosas" seis perguntas (o quê?, quem? quando? onde? como? por quê?), que serão que serão explicadas em detalhes ao longo do texto (Bahia,1990,p. 44).

No telejornalismo, o lead foi adaptado às condições da televisão. A cabeça da matéria - a abertura da informação televisiva lida, na maioria das vezes, pelo apresentador, reportagem: está normalmente relacionada com a principal informação da Squirra (1995) comenta que os títulos, no telejornalismo, são equivalentes aos leads do jornalismo impresso. É o elemento de destaque da notícia dentro da avalanche de dados do telejornal.

Pelo apresentado até agora, a função do jornalismo ficaria restrita a uma simples reprodução da realidade social mediante um "instrumental" de regras mecânicas a serem acionadas pelos jornalistas no momento de escreverem seus textos: um relato descritivo a partir do lead do fato mais importante.

Acreditamos que esta perspectiva é reducionista. Nesse sentido, entendemos que o jornalismo não é um espelho da realidade, mas uma forma de conhecimento social, que constrói diariamente o mundo que nos cerca. No processo de descrever um fato a notícia define e dá forma a esse fato (Tuchman, 1983, p. 197-198).

Na produção de notícias, temos, por um lado, a cultura profissional; e por outro, as restrições ligadas à organização do trabalho sobre as quais são criadas convenções profissionais que contribuem para definir a notícia e legitimam o processo produtivo, desde a captação do acontecimento, passando pela produção, edição e até a apresentação.

"As exigências organizativas e estruturais e as características técnico-expressivas, próprias de cada meio de comunicação de massa, são elementos fundamentais para a determinação da reprodução da realidade social fornecida pelos mass media". (Wolf, 1994, p. 166).

É dentro deste contexto que vemos o lead no jornalismo. Submetido às estruturas organizacionais de cada veículo (jornal, rádio e tevê), a uma cultura profissional e às rotinas de produção da notícia vai apresentar características dependendo do suporte (meio) em que está sendo trabalhado.

Por isso, neste segundo momento do trabalho, procuraremos apontar algumas semelhanças e diferenças entre a notícia do jornal e da televisão. E, a partir da comparação procurar mostrar que o lead no telejornalismo apresenta características bem peculiares.

Este estudo comparativo tem por base a pesquisa realizada por Paul Weaver sobre as notícias de jornal e as notícias de televisão(Traquina, 1993, p. 295-305). Comecemos pelas semelhanças. Em ambos os casos, as notícias são variedades do jornalismo que têm como finalidade o relato de acontecimentos atuais. Os discursos jornalísticos estão presos há uma dupla contemporaneidade. O presente como "assunto" e o presente como perspectiva no tempo em que o fato é descrito. Em outras palavras, o jornalismo é o discurso da atualidade (Correia, 1997, p. 153).

A notícia de jornal e a de televisão também são semelhantes na cobertura dos acontecimentos diários por meio da reportagem, descrição factual que um observador (repórter) em cima do fato em questão viu e ouviu. Há uma preocupação com o 
concreto, o imediato e a fidelidade à particularidade dos acontecimentos. A reportagem é o lugar de "sublimação" do jornalismo, onde a narrativa, inerente a este campo, se faz presente com mais intensidade. (Ferrari \& Sodré, 1986).

Em terceiro lugar, tanto as notícias de rádio como as de televisão são semelhantes porque produzidas por instituições que têm como objetivo principal a produção das mesmas. Além disso, todo o processo de construção da notícia é de responsabilidade de uma pessoa que o tempo todo vive em função disso: o jornalista. A finalidade de qualquer instituição informativa é de dar relatos sobre acontecimentos significativos, interessantes e importantes (Tuchman, 1983).

As notícias de jornal e de televisão são semelhantes ainda por estarem permanentemente submetidas à prova dos vereditos do mercado, através da sanção, direta, da clientela, ou indireta, do índice de audiência. Ambas estão submetidas a uma "ditadura da audiência". A principal fonte de rendimento das empresas jornalísticas é a publicidade.

Por fim e, como conseqüência da pressão da audiência, os jornais e, principalmente, as televisões estão constantemente em busca do "furo".

Em outras palavras, a concorrência pelo leitor e pelo telespectador toma a forma de concorrência pela prioridade, pelas notícias mais novas, que são usados como trunfos na conquista da audiência.

"Inscrita na estrutura e nos mecanismos de campo, a concorrência pela prioridade atrai e favorece os agentes dotados de disposições profissionais que tendem a colocar toda a prática jornalística sob o signo da velocidade(ou da precipitação) e da renovação permanente". (Bordieu, 1997, p. 107).

\section{As notícias de jornal vs as notíci- as de televisão}

Observamos as semelhanças entre as notícias de jornal e de televisão., entraremos agora nas diferenças. A primeira, de ordem es- trutural, é que o jornal oferece um "menu" das informações do dia. A partir da leitura das manchetes de capa, a pessoa tem a opção de escolher entre elas aquela que deseja ler por primeiro e dirigir-se à página onde ela se encontra.

Com o telejornal dá-se justamente o contrário. As notícias são selecionadas, elaboradas e organizadas de modo a serem vistas integralmente pelos telespectadores sem diminuir o tamanho ou interesse da audiência ao longo do programa.

O número de informações de um noticiário televisivo é menor do que no jornal e há sempre uma preocupação com um equilíbrio num todo relativamente coerente e integrado. De certa forma, o jornalista vê-se obrigado a um constante "jogo de sedução" para manter a atenção do espectador até o boa-noite dos apresentadores.

Um outro aspecto a ser considerado é que as notícias televisivas são um resumo dos principais acontecimentos do dia. $\mathrm{Na}$ maioria das vezes os assuntos são abordados de uma forma superficial e fragmentada. Já no jornal as notícias podem ser tratadas de uma forma mais profunda, mais analítica, proporcionando desta maneira uma visão mais contextualizada do fato.

A segunda grande diferença entre os dois media está relacionada com os critérios relativos aos limites de produção característicos de cada veículo. A televisão é tanto visual como auditiva. O mesmo não acontece com o jornal que apóia-se na narrativa falada. Essa diferença óbvia tem, no entanto, conseqüências decisivas na execução das funções narrativas de ambos.

O repórter de jornal adota uma narrativa mais impessoal, dificilmente fala na primeira pessoa. Ao longo da sua reportagem raramente faz referências aos seus próprios atos na observação dos acontecimentos e dos fatos. O jornal procura ocultar sistematicamente qualquer traço da pessoa real que escreve. $\mathrm{O}$ que permanece na notícia é uma sucessão de declarações (Gonçalves, 1994, p. 57).

Na televisão acontece o contrário. É 
sobretudo uma "voz pessoal" que apresenta as notícias diariamente. $\mathrm{O}$ rosto, o corpo, a postura da pessoa, seus gestos são partes integrantes do produto informativo. Os repórteres e apresentadores transformam-se praticamente em "artistas" da informação. Um exemplo prático disso foi a polêmica em torno do substituto do apresentador Cid Moreira, no Jornal Nacional.

Finalmente, a notícia televisiva é diferente da notícia do jornal porque empresta muito mais força ao espetáculo. Esse aspecto está intimamente relacionado com outros dois tratados anteriormente. A informação televisiva em função dos limites do meio de comunicação(as pessoas não podem voltar ao começo da notícia nem virar a página para tirar alguma dúvida). por isso, têm que procurar durante todo o programa "seduzir" o telespectador com objetivo de cativar e manter a audiência (compromissos com os anunciantes).

Apresentadas algumas semelhanças e diferenças entre as notícias de jornal e as de televisão, entramos na última parte deste estudo onde pretendemos levantar algumas pistas sobre a construção do lead na notícia televisiva.

A notícia padrão de qualquer jornal é organizada de acordo com a "pirâmide invertida".

No lead, de uma maneira geral, vamos encontrar um resumo da informação e, na seqüência, nos demais parágrafos, os dados complementares e explicativos do que foi tratado na abertura da matéria. Essa descrição é feita de uma forma decrescente, da informação "mais importante" a "menos importante".

Um dos objetivos é possibilitar o acesso rápido do leitor as principais informações da matéria. Num breve passar de olhos ele poderá decidir se já leu o que interessa.

Outro objetivo, ainda em uso no jornalismo, é cortar a matéria em função das necessidades de espaço e tempo das empresas jornalísticas, bem como de seus compromissos comerciais.

\section{- lead no telejornalismo}

$\mathrm{Na}$ notícia televisiva o processo não se dá da mesma forma. A, notícia na televisão é construída para ser entendida na sua totalidade. Senão vejamos. A cabeça de uma matéria de televisão - abertura da notícia lida pelo apresentador - tem como função chamar o videotape(VT) - a matéria elaborada pela reportagem. Em outras palavras a notícia é a "cabeça" da matéria mais o VT. A supressão de uma destas partes tornaria incompreensível a informação.

$\mathrm{O}$ assunto que uma matéria de televisão trata perpassa todo o material editado. A narrativa no telejornalismo tem começo, meio e fim, o que não acontece nas matérias de jornal. As informações, sons e imagens são selecionadas para ilustrar o desenvolvimento do tema.

“... cada suporte, além da especificidade das suas condições de produção resultante das suas características próprias, constrói em suas maneiras com as quais trata de se oferecer como meio, que tenta dar conta de uma inteligibilidade do real"(Fausto Neto, 1991, p.35).

No telejornalismo, mais do que no jornal, o processo de edição da notícia, recontextualização dos fatos é submetido ao rígido formato estabelecido pelo noticiário televisivo.

“A fragmentação dos conteúdos e da imagem da realidade social situa-se, exatamente, entre esse dois movimentos: por um lado, a extração dos acontecimentos do seu contexto; por outro, a reinserção dos acontecimentos noticiáveis no contexto construído pela 'confecção' pelo formato do produto informativo "(Wolf, 1994, p.219).

Wolf explica ainda que é dentro do quadro do formato que acontece a adição de sentido ligado à aproximação de duas notícias entre si. os critérios de acerto do ritmo do noticiário, às inferências que se podem tirar da ordem em que estão dispostas as próprias notícias. Em outras palavras, a produção da atividade informativa é racionalizada. 
A importância da imagem no telejornalismo ressaltada, principalmente, pelos "videojornalistas" está associada à necessidade de que a informação televisiva tem de representar de uma forma sintética, breve, visualmente coerente o objeto da notícia.

Uma das explicações para a preocupação dos editores com uma imagem forte, que pode até salvar a matéria pode ser encontrada na definição de Gans (1980, p.9093) sobre o higligthing, que é a seleção dos aspectos mais importantes de um fato, ação ou personagem, deixando de fora os aspectos que não pareçam "novos"ou "dramáti$\cos ^{\prime \prime}$.

O highlighting e a edição contribuem para deixar de lado na elaboração da notícia tendências inerentes à dinâmica social, ressaltando os desvios à norma. É já por demais conhecida a frase que procura explicar o que é notícia dizendo que se um cachorro morde um homem, não temos notícia, mas se o homem morde o cachorro, ai temos notícia.

Essa preocupação leva o jornalismo televisivo a dar uma cobertura desproporcionada a fatos, ou aspectos que são espetaculares e espetacularmente gravados. Como mostra Bordieu (1997), ela está fortemente influenciada pela pressão comercial que se torna visível na luta desenfreada pelos índices de audiência.

De que forma isso vai influir o lead no telejornalismo? Com base no que foi apresentado levantamos duas hipóteses. A primeira é o que o lead tradicional do jornal que traz na abertura da matéria o fato mais importante da reportagem é subvertido na televisão.

Ele dá lugar a uma abertura da matéria que não vai necessariamente se preocupar com o fato mais importante da notícia, mas com o detalhe mais atraente, mais sedutor ao telespectador já que é preciso prender a audiência. É cada vez mais comum nos telejornais do horário nobre assistirmos aos apresentadores lerem as notícias preocupando-se mais com o aspecto pitoresco da matéria, deixando de lado a informação principal.

A segunda hipótese remete ao que foi tratado anteriormente. A notícia de televisão como é elaborada para ser assistida na sua totalidade não teria necessariamente um lead, mas seria ela toda um grande $l i-$ $d \tilde{a} o^{3}$, reforçando ainda mais os aspectos de banalização, superficialidade e espetacularização da notícia televisiva.

O estudo realizado por Daniel Hallin e Paolo Mancini (1993,p. 307-325) sobre a estrutura política e a forma representacional nas notícias televisivas dos Estados Unidos e da Itália, oferece algumas importantes contribuições para o debate. A pesquisa mostra que as TVs americanas para manter a audiência usam um conjunto de convenções para envolver o telespectador emocionalmente.

Já na televisão italiana, por contraste, os índices de audiência não são uma preocupação permanente. Motivo: as televisões americanas são de propriedade de empresas privadas com fins lucrativos(sistema privado) e a principal rede transmissora nacional da Itália, Radiotelevisione Italiana, RAI, é propriedade do Estado e dirigida por um Conselho eleito do parlamento (sistema público).

Como estamos ainda num trabalho inicial de pesquisa novos aspectos deverão ser acrescentados e já estão sendo acrescentados ao estudo. Uma das preocupações é estudar os- efeitos que o campo jornalístico e, através dele, a lógica do capital, a pressão do mercado, determinam sobre a receito e os demais campos da sociedade (cultural e político)

\section{Notas}

1 Doutorando em Comunicação/UFRJ, professor UFES e professor licenciado Unisinos

2 Mestranda em Comunicação/UFRJ e jornalista

3 As informações são distribuídas ao longo de um ou dois 
minutos de matéria (tempo médio de duração de uma reportagem) com 0 objetivo de prender 0 telespectador, de tornar a apresentação do assunto mais interessante.

\section{Referências}

AMARAL, Luís. Técnica de jornal e periódico. $2^{\mathrm{a}}$.ed. Rio de Janeiro: Tempo Brasileiro/MEC, 1987.

BAHIA, Juarez. Jornal, história e técnica. 4a ed. São Paulo: Ática, 1990.

BERGER, Peter 1.; LUCKMANN, Thomas. A construção social da realidade. 12a .ed.: Petrópolis: Vozes, 1995.

BORDIEU, Pierre. Sobre a televisã̃o. Rio de Janeiro: Jorge Zahar, 1997.

CAPARELLI, Sérgio; STUMPF, Ida Regina C (orgs). Teses e dissertações em comunicação no Brasil(1992-1996). Porto Alegre: PPGCOM/UFRGS, 1998.

CORREIA, Fernando. Os jornalistas e as notícias. Lisboa: Caminho, 1998.

FAUSTO NETO, Antônio. 0 impeachment da televisão. Como se cassa um presidente. Rio de Janeiro: Diadorim, 1995.

FERRARI, Maria Helena; SODRÉ, Muniz. Técnica de reportagem. Notas sobre a narrativa jornalística. $2^{\text {a }}$.ed. São Paulo: Summus, 1986.

FONTCUBERTA, Mar de. La noticia pistas para percebir el mundo. Barcelona: Paidós, 1993.

GANS, Herbert J. A study of CBS Evenning News and Newsweek and Time. New York: Vintage Books, 1980.

GENRO, Adelmo. O segredo da pirâmide. Porto Alegre: Tchê, 1977.

GONÇALVES, Elias Machado. Salvador, ano 2, n², 1994. A essência do real nas notícias. Pauta Geral. Salvador, ano 2, $n^{0} 2,1994$.

MANCINI, Paolo; HALLIN, Daniel C. "Falando do presidente: a estrutura política e a reforma representacional nas notícias televisivas dos Estados Unidos e da Itália". In: TRAQUINA, Nelson(org.) Jornalismo: questões, teorias e "estórias". Lisboa: Vega, 1993.

MARQUES DE MELO, José. A opinião no jornalismo brasileiro. $2^{\mathrm{a}}$.ed. Petrópolis: Vozes, 1994.

QUNITERO, Alejandro Pizarroso. Evolução histórica da imprensa nos Estados Unidos. In: QUINTERO, Alejandro Pizarroso(org.) História da imprensa. Lisboa: Planeta, 1996.

SIGAL, Leon V. Sources make the news. In: MANOFF, Robert Karl; SCHUDSON, Michael. Reading the newws. New York: Pantheon Books, 1986.

TRAQUINA, Nelson(org.). Jornalismo: questões, teorias e "estórias". Lisboa: Vega, 1993.

TUCHMAN, Gay. La producción de Ia noticia. Estudo sobre la construcción de la realidade. Barcelona: Gilii, 1983.

WEAVER, Paul H. "As notícias de jornal e as notícias de televisão". In: TRAQUINA, Nelson(org.). Jornalismo: questões, teorias e "estórias" ". Lisboa: Vega, 1993

WOLF, Mauro. Teorias da comunicação. $3^{\mathrm{a} e d .}$ Lisboa: Presença, 1994. 